\title{
Synthesis of Nanocrystalline WC Single-Phase Refractory via Mechanical Milling
}

\author{
Mansour Razavi, Mohammad Reza Rahimipour, and Rahim Yazdani-Rad \\ Department of Ceramic, Materials and Energy Research Center (MERC), P.O. Box 14155-4777, Tehran, Iran \\ Correspondence should be addressed to Mansour Razavi, m-razavi@merc.ac.ir
}

Received 7 March 2011; Revised 7 July 2011; Accepted 9 August 2011

Academic Editor: Rakesh Joshi

Copyright ( $) 2011$ Mansour Razavi et al. This is an open access article distributed under the Creative Commons Attribution License, which permits unrestricted use, distribution, and reproduction in any medium, provided the original work is properly cited.

In this paper the possibility of production of nanocrystalline WC single-phase by mechanical milling has been investigated. The raw materials containing tungsten and carbon with WC as nucleation were milled in a planetary ball mill and sampled in different times. Studies showed that after 75 hours of milling the WC with $\mathrm{W}_{2} \mathrm{C}$ was produced and remained constant in higher milling time. Adding WC to raw materials at the beginning process leads to the fact that after 50 hours of milling only WC was synthesized without undesirable $\mathrm{W}_{2} \mathrm{C}$ phase. This material remained stable until higher times of milling too. From broadening of XRD peaks, the crystalline size in synthesized WC was estimated in nanometer scale which lower than the system containing primary WC, and it means that the strain in this system was lower than first system.

\section{Introduction}

Tungsten carbide (WC) is an inorganic chemical compound. In its most basic form, it is a fine gray powder, but it can be pressed and formed into shapes for use in industrial machinery, tools, abrasives, as well as jewelry due to high hardness $(2600 \mathrm{HV})$, good toughness, high melting point $\left(2780^{\circ} \mathrm{C}\right)$, high wear resistance, suitable resistance in thermal shock, and good thermal conductivity. Also natural resistance to oxidation and corrosion of this material at high temperature cause the increase usage of this material as coating in high temperature [1-6].

Tungsten carbide can be prepared by reaction of tungsten metal and carbon at $1400-2000^{\circ} \mathrm{C}$ under vacuum or inner gas with high purity, is the conventional method for production of this material but this process which still needs high cost $[2,7]$. Other methods include a patented fluid bed process that reacts either tungsten metal or blue $\mathrm{WO}_{3}$ with $\mathrm{CO} / \mathrm{CO}_{2}$ mixture and $\mathrm{H}_{2}$ between 900 and $1200^{\circ} \mathrm{C}$ [8]. In addition to self-propagating techniques, organometallic precursor, solution state, and electrochemical methods have been utilized for production of this carbide, but each of these methods has their specific advantages and disadvantages [9]. Due to limitations for synthesizing this material with traditional methods (mentioned above) and considering the fact that range of tungsten carbide in the phase diagram is narrow, mechanical milling can be a suitable method for production of this in nanometer scale $[8,10]$.

There are two well-characterized compounds of tungsten and carbon, WC and tungsten semicarbide, $\mathrm{W}_{2} \mathrm{C}$. Usually during the production process of tungsten carbide, WC and $\mathrm{W}_{2} \mathrm{C}$ are synthesized together $[2,10-13]$. Presence of $\mathrm{W}_{2} \mathrm{C}$ with WC can reduce mechanical and tropological properties of final materials [14-16]. According to this phenomenon, this paper has tried to synthesize nanocrystalline via mechanical milling.

\section{Experimental}

In this work, powder mixture of tungsten, amorphous carbon black as carbon source, and tungsten carbide with purity and mean particle size of $>99.5 \%$ and $1 \mu \mathrm{m},>99 \%$ and $0.5 \mu \mathrm{m}$, and $>99 \%$ and $1 \mu \mathrm{m}$ have been examined. These materials were milled in a high-energy ball mill as high energetic ball mill by stoichiometric ratio $(\mathrm{W}+\mathrm{C}=\mathrm{WC})$. The sampling has been done at 1, 10, 50, 75, 100, and 150 hours. For protecting materials from oxidation, the argon gas 
with purity of $99.99 \%$ and pressure of $250 \mathrm{kPa}$ was charged in cup of ball mill. The used cup and balls made from high chrome stainless steel. The ratio of balls to powder was $1: 10$ and from 4,3 and 3 balls of 21,16 , and $10 \mathrm{~mm}$, respectively was used in all of tests.

For determination of phase type and synthesized components as well as calculation of crystalline size from Scherrer and Williamson-Hall methods [17, 18], XRD instrument (Siemens model) with voltage and current of $25 \mathrm{~mA}$ and $30 \mathrm{kV}$ was employed, respectively. Type of X-ray in this device was $\operatorname{Cuk} \alpha$ with wave length of $1.5405 \AA$. For determination of full-width at half-maximum (FWHM), PANalytical X'Pert HighScore software was used. X'Pert HighScore uses the Pseudo-Voigt profile function, which is the weighted mean between a Lorentz and a Gauss function:

$$
G_{i k}=\gamma \frac{C_{0}^{1 / 2}}{H_{k} \pi}\left[1+C_{0} X_{i k}^{2}\right]^{-1}+(1-\gamma) \frac{C_{1}^{1 / 2}}{H_{k} \pi^{1 / 2}} \exp \left[-C_{1} X_{i k}^{2}\right]
$$

where $C_{0}=4, C_{1}=4 \times \ln 2, H_{k}$ is FWHM of the $k$ th Bragg reflection, and $X_{i k}=\left(2_{\theta i}-2_{\theta k}\right) / H_{k} \cdot \gamma$ is a refinable mixing parameter describing the amount of Gaussian profile versus the amount of Lorentzian profile, and thus describing the overall profile shape. Finally for studying of the microstructure of the material, transmission electron microscope (TEM) with the voltage of $25 \mathrm{kV}$ was used.

\section{Results and Discussions}

$\mathrm{X}$-ray patterns of samples containing tungsten and carbon, which were milled to 150 hours, are presented in Figure 1. As it can be seen in this figure, to 50 hours, milling did not affect the type of phases and the tungsten was the only phase that appears in patterns. As it can be noted, since the carbon source was selected in amorphous form, the carbon peak cannot be seen in the diffraction pattern. However, due to egregious differences between the mass absorption coefficients (MACs) of tungsten and carbon $\left(172.07 \mathrm{~cm}^{2} / \mathrm{gr}\right.$ versus $4.30 \mathrm{~cm}^{2} / \mathrm{gr}$ ), even if the carbon was not amorphous, the possibility of detecting of the carbon peaks has been very weak. From this figure, it is obvious that by increasing the ball milling time, the peaks of materials were broadened slightly, that is, by increasing the time the crystalline size has been reduced. Also by increasing the milling time, area of the under peak 100 of tungsten (100) was reduced that illustrates the gradual consumption of raw materials (Figure 2) [18].

By increasing the milling time reaching 75 hours, the carbide tungsten peaks containing $\mathrm{WC}$ and $\mathrm{W}_{2} \mathrm{C}$ with tungsten appear (Figure 1). After 100 hours of milling, tungsten peaks disappeared completely, and the amount of WC phase was increased too. From mentioned software, the ratio of visible material in X-ray diffraction pattern in Figure 1 has been calculated. These pieces of information are listed in Table 1. However, by increasing the time, the ration of amount of $\mathrm{WC}$ to $\mathrm{W}_{2} \mathrm{C}$ was raised, but in 150 hours the $\mathrm{W}_{2} \mathrm{C}$ phase was not been eliminated from synthesized materials.

In order to eliminate the undesirable $\mathrm{W}_{2} \mathrm{C}$ phase from the synthesized materials, $1 \% \mathrm{wt}$. of WC with stoichiometric

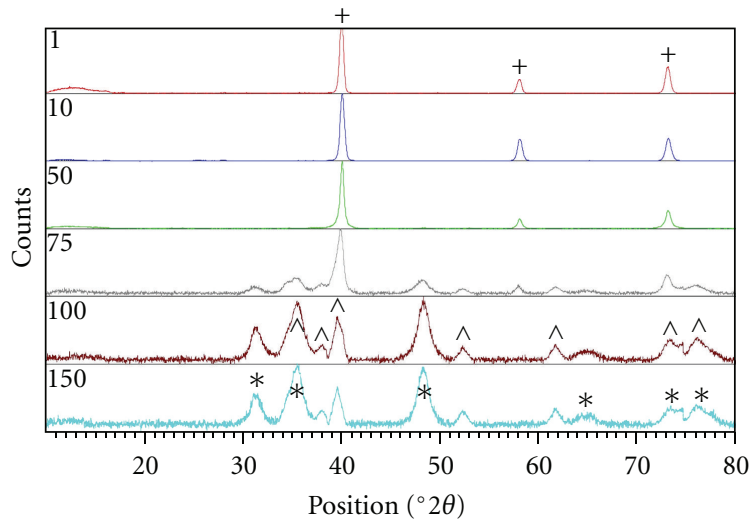

FIGURE 1: X-ray patterns of samples contain tungsten and carbon which were milled from 1 to 150 hours $\mathrm{W}(+), \mathrm{WC}(*), \mathrm{W}_{2} \mathrm{C}(\wedge)$.

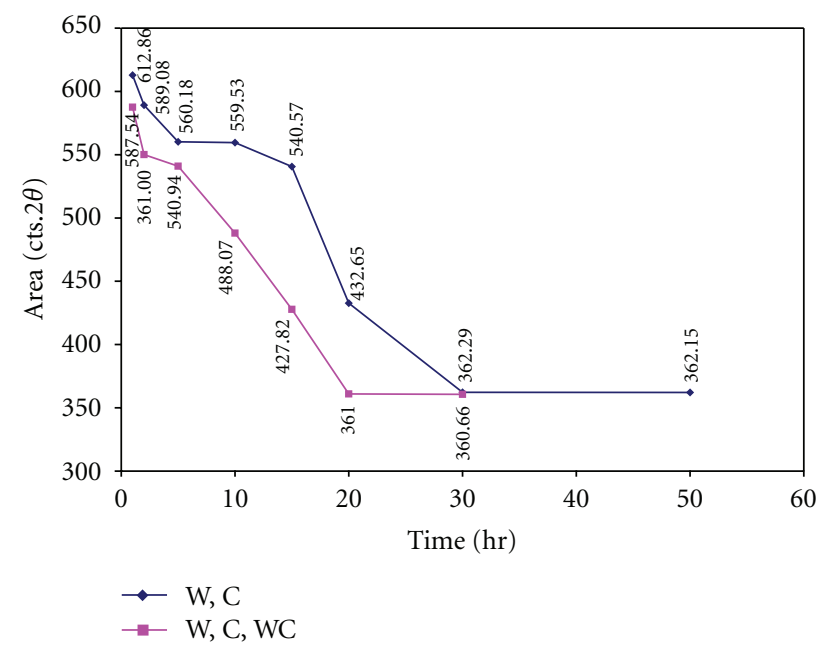

Figure 2: The change of area of under peak 100 of tungsten versus milling time.

ratio of $\mathrm{W}$ and $\mathrm{C}$ was charged as the raw materials in cup of ball mill. The results of X-ray pattern from the mixed materials up to 150 hours are showed in Figure 3 . As it is obvious, to 10 hours of milling time, tungsten peaks were only phases observed in these patterns. Similar to previous mixture, by increasing the time of milling, the broadening of peaks was increased slightly and the area under peak 100 (Figure 2) was decreased. As it can be seen in Figure 2, the area under peak 100 in the sample contains $1 \% \mathrm{wt}$. WC is smaller than the other system. Since the mass adsorption coefficient of WC $\left(161.78 \mathrm{~cm}^{2} / \mathrm{gr}\right)$ is smaller than $\mathrm{W}$, hence the intensity of peaks and area under the peaks of sample which contains WC were smaller than first mixture. Milling up to 50 hours could cause the synthesizing of monocarbide tungsten partially with primary W. By increasing the milling time, the $\mathrm{W}$ has been reduced while the amount $\mathrm{WC}$ was increased that in time of 100 hours the peak trace of W disappeared and the only visible peak belongs to WC. The WC phase until 150 hours remained stable and did not show any changes. Quantity of phases in final composition, 
TABLE 1: The ratio of visible material in X-ray diffraction pattern.

\begin{tabular}{lccccccc}
\hline & & 1 & 10 & 50 & 75 & 100 & 150 \\
\hline \multirow{2}{*}{ W-C system } & $\mathrm{W}$ & 1.000 & 1.000 & 1.000 & 0.228 & - & - \\
& $\mathrm{WC}$ & - & - & - & 0.161 & 0.549 & 0.581 \\
& $\mathrm{~W}_{2} \mathrm{C}$ & - & - & - & 0.611 & 0.451 & 0.419 \\
\hline \multirow{2}{*}{$\mathrm{W}-\mathrm{C}-\mathrm{WC}$ system } & $\mathrm{W}$ & 1.000 & 1.000 & 0.936 & 0.544 & - & - \\
& $\mathrm{WC}$ & - & - & 0.064 & 0.456 & 1.000 & 1.000 \\
\multirow{2}{*}{$\mathrm{W}-\mathrm{C}-\mathrm{Al}_{2} \mathrm{O}_{3}$ system } & $\mathrm{WC}$ & - & - & - & - & - & 0.785 \\
& $\mathrm{~W}_{2} \mathrm{C}$ & - & - & - & - & - & 0.215 \\
\hline
\end{tabular}

according to X-ray pattern and mentioned software, are listed in Table 1. As it was mentioned previously, with reducing the synthesis time, WC was produced which can be attributed to the following phenomena.

(1) Formation of tungsten carbide from tungsten and carbon can be divided into three stages: first nucleation, second growth of these nucleations (grain growth), and finally reaching grains of each other and stop their growth. In a mixture containing WC, it can be said that all or part of the first-mentioned stage has happened, so at the end of process the materials which from all raw materials should have been reduced [19].

(2) The presence of the hard ceramic phase such as WC accelerates the rate at which the milling process reaches completion. Also these particles increase local deformation which improves the particle welding process. Beside this, the higher local deformation imposed by reinforcement particles increases the deformation hardening, which itself helps the fracture phenomenon. The small hard brittle particles in the matrix act as small milling agents, which lead to reduce the steady state milling time [20].

(3) From thermodynamic viewpoint, one can conclude that the stability of $\mathrm{WC}$ and $\mathrm{W}_{2} \mathrm{C}$ phases at each temperature is expected regarding the EllinghamRichardson diagram of these two materials in Figure 4 [21]. On the basis of this figure, $\mathrm{W}_{2} \mathrm{C}$ is stable at temperature over $1515^{\circ} \mathrm{K}$, and below this point WC is stable instead. Hence in a mixture containing tungsten and carbon at temperature higher than critical value, the $\mathrm{W}_{2} \mathrm{C}$ phase was synthesized and has been cooled in a nonequilibrium manner and can be expected $\mathrm{W}_{2} \mathrm{C}$ as remained phase in final components too. But in a mixture which contains primary WC, some amount of heat from reaction between tungsten and carbon was adsorbed by this carbide and then the temperature did not reach a critical value. Hence, all of synthesized phases were monocarbide tungsten.

If 2 nd and 3rd hypotheses were corrected, then this treatment should be applied by adding of other additives. For proving of theses hypotheses, $1 \%$ wt. $\alpha$-alumina was added to a mixture of tungsten and carbon and these

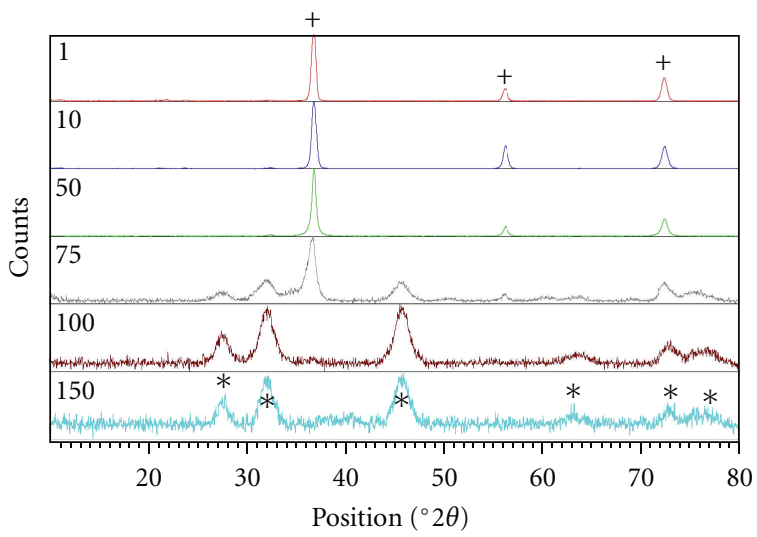

Figure 3: X-ray patterns of samples contain W, C, and WC which were milled from 1 to 150 hours $\mathrm{W}(+), \mathrm{WC}(*)$.

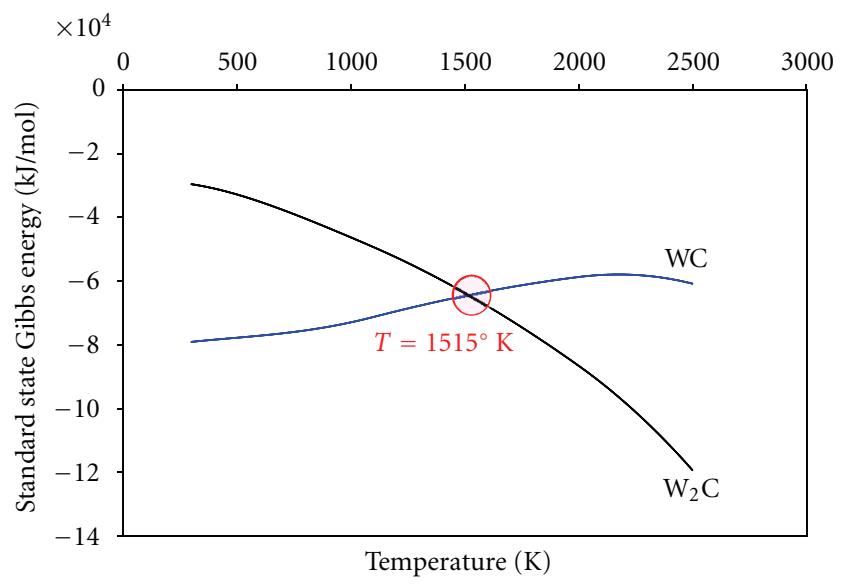

FIGURE 4: Ellingham-Richardson diagram of WC and $\mathrm{W}_{2} \mathrm{C}$ phases.

materials milled to 150 hours with the former experimental conditions. X-ray diffraction pattern of this mixture and amount of produced phases are shown in Figure 5 and Table 1, respectively. Despite the formation of $\mathrm{W}_{2} \mathrm{C}$ in the final composition, the amount of this phase in the present mixture was much less than the mixture without any additive which can be confirmed in the mentioned hypotheses.

In Figure 6, Williamson-Hall curve for determination crystalline size and mean strain of synthesized WC phase are shown. The results of this figure are listed in Table 2. 
TABLE 2: Crystalline size and mean strain of synthesized WC.

\begin{tabular}{|c|c|c|c|c|c|}
\hline \multirow{2}{*}{ Time (hr) } & \multicolumn{2}{|c|}{$y=a x+b$} & \multirow{2}{*}{ crystalline size $(\mathrm{nm})$} & \multirow{2}{*}{ mean strain $(\%)$} & \multirow[t]{2}{*}{ Determination Method } \\
\hline & $a$ & $b$ & & & \\
\hline \multicolumn{6}{|c|}{$\mathrm{W}-\mathrm{C}$ mixture } \\
\hline 75 & - & - & 69.21 & 0.71 & Scherrer \\
\hline 100 & 0.018 & 0.004 & 39.60 & 1.80 & $\mathrm{~W}-\mathrm{H}$ \\
\hline 150 & 0.025 & 0.007 & 20.09 & 2.51 & $\mathrm{~W}-\mathrm{H}$ \\
\hline \multicolumn{6}{|c|}{ W-C-WC mixture } \\
\hline 75 & 0.015 & 0.003 & 46.20 & 1.50 & $\mathrm{~W}-\mathrm{H}$ \\
\hline 100 & 0.020 & 0.005 & 30.13 & 1.97 & $\mathrm{~W}-\mathrm{H}$ \\
\hline 150 & 0.031 & 0.017 & 8.35 & 3.06 & $\mathrm{~W}-\mathrm{H}$ \\
\hline \multicolumn{6}{|c|}{$\mathrm{W}-\mathrm{C}-\mathrm{Al}_{2} \mathrm{O}_{3}$ Mixture } \\
\hline 150 & 0.026 & 0.008 & 18.00 & 2.57 & $\mathrm{~W}-\mathrm{H}$ \\
\hline
\end{tabular}

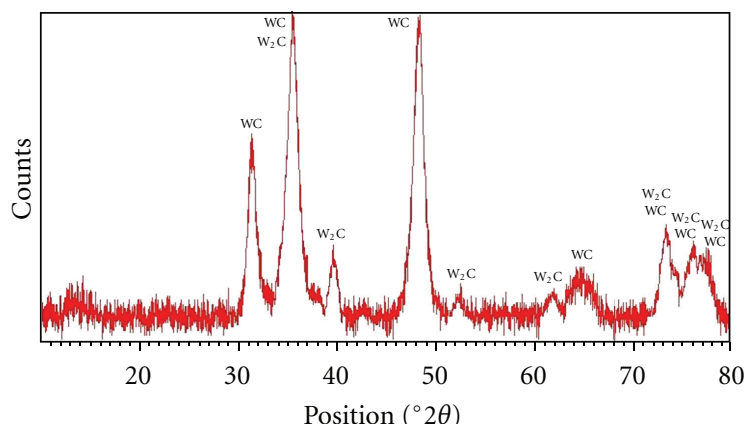

FIGURE 5: X-ray patterns of samples containing $1 \%$ wt. $\alpha$-alumina.

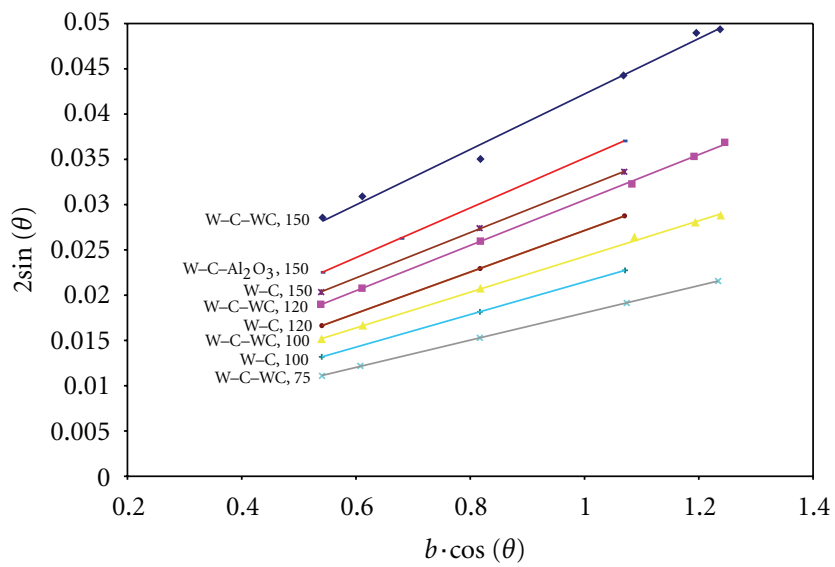

FIGURE 6: Williamson-Hall curve for determination crystalline size and mean strain of synthesized WC phase

As it can be seen in Table 2 and Figure 7 , the range of this carbide is in nanometer scale $(8-69 \mathrm{~nm})$ where by increasing the milling time, the crystalline size is reduced and mean strain increased. Furthermore, the crystalline size of mixture containing WC and $\mathrm{Al}_{2} \mathrm{O}_{3}$ was smaller than the system without additive. This fact confirms the mentioned hypotheses. Also the mean strain in this system became higher than first system which had higher reaction

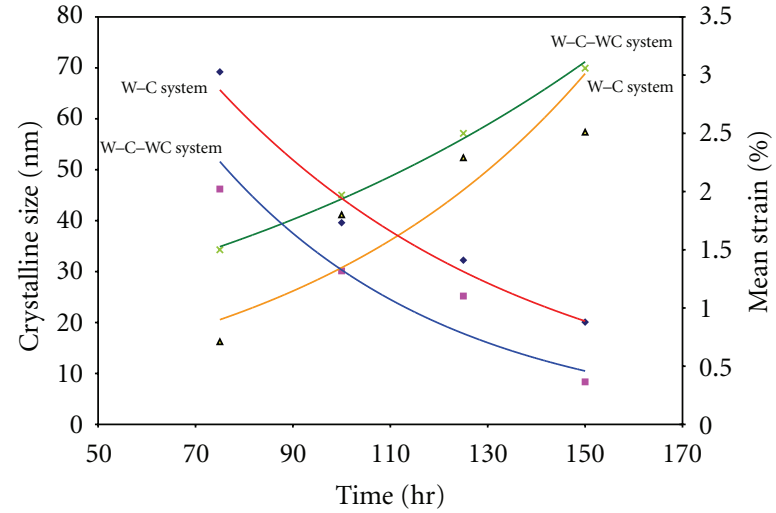

FIGURE 7: The change of crystalline size and mean strain of WC versus milling time.

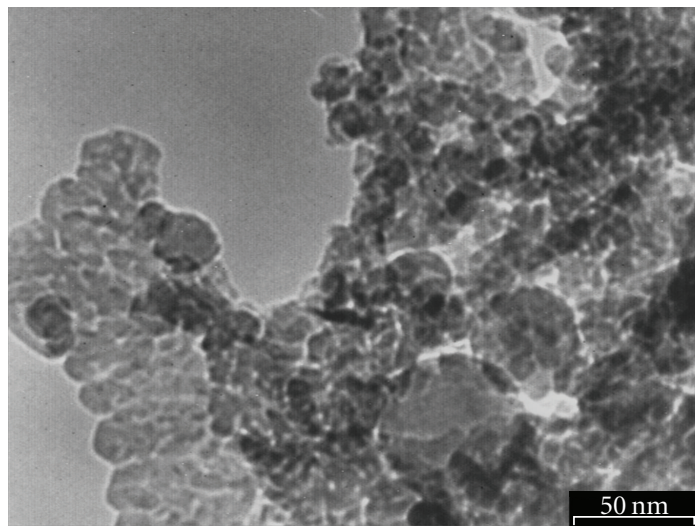

FIGURE 8: The TEM micrograph of samples with primary WC milled for 150 hours.

temperature and hence produce lower mean strain. The TEM microstructure of sample with primary WC milled for 150 hours is presented in Figure 8. This micrograph confirms the nanometer scale of the particles. Also it confirms the results of Williamson-Hall method. 


\section{Conclusion}

By adding of WC to the mixture of tungsten and carbon black, it can lead to synthesized WC. However, the synthesis time has been reduced significantly. This phenomenon can be attributed to the reduction of microscopic temperature in raw material mixture and thereby the production of WC as a low temperature phase. Also adding WC can act as small ball mill which helps the milling process. The existence of primary WC as nucleation could be another reason for this phenomenon. By increasing the time of milling, the synthesized carbide crystalline was fine in the scale of nanometer $(8-70 \mathrm{~nm})$ and the mean strain of the system was increased.

\section{References}

[1] M. S. El-Eskandarany, M. Omori, M. Ishikuro et al., "Synthesis of full-density nanocrystalline tungsten carbide by reduction of tungstic oxide at room temperature," Metallurgical and Materials Transactions A, vol. 27, no. 12, pp. 4210-4213, 1996.

[2] G. M. Wang, S. J. Campbell, A. Calka, and W. A. Kaczmarek, "Synthesis and structural evolution of tungsten carbide prepared by ball milling," Journal of Materials Science, vol. 32, no. 6, pp. 1461-1467, 1997.

[3] B. V. Krishna, V. N. Misra, P. S. Mukherjee, and P. Sharma, "Microstructure and properties of flame sprayed tungsten carbide coatings," International Journal of Refractory Metals and Hard Materials, vol. 20, no. 5-6, pp. 355-374, 2002.

[4] R. Schwetzke and H. Kreye, "Microstructure and properties of tungsten carbide coatings sprayed with various highvelocity oxygen fuel spray systems," Journal of Thermal Spray Technology, vol. 8, no. 3, pp. 433-439, 1999.

[5] Y. Shinoda, T. Akatsu, and F. Wakai, "Integrated molding of nanocrystalline tungsten carbide powder with stainless steel," Materials Science and Engineering B, vol. 148, no. 1-3, pp. 145$148,2008$.

[6] W. Acchar, C. A. Cairo, and A. M. Segadães, "Effect of tungsten carbide additions on the microstructure and properties of hotpressed alumina," Materials Science and Engineering A, vol. 406, no. 1-2, pp. 74-77, 2005.

[7] M. S. El-Eskandarany, "Fabrication and characterizations of new nanocomposite $\mathrm{WC} / \mathrm{Al}_{2} \mathrm{O}_{3}$ materials by room temperature ball milling and subsequent consolidation," Journal of Alloys and Compounds, vol. 391, no. 1-2, pp. 228-235, 2005.

[8] S. Mi and T. H. Courtney, "Synthesis of WC and WC-Co cermets by mechanical alloying and subsequent hot isostatic pressing," Scripta Materialia, vol. 38, no. 1, pp. 171-176, 1998.

[9] J. H. Ma and Y. H. Du, "Synthesis of nanocrystalline hexagonal tungsten carbide via co-reduction of tungsten hexachloride and sodium carbonate with metallic magnesium," Journal of Alloys and Compounds, vol. 448, no. 1-2, pp. 215-218, 2008.

[10] M. L. Öveçoğlu and B. Özkal, "Mechanochemical synthesis of WC powders by mechanical alloying," Key Engineering Materials, vol. 264-268, no. I, pp. 89-92, 2004.

[11] S. Bolokang, C. Banganayi, and M. Phasha, "Effect of C and milling parameters on the synthesis of WC powders by mechanical alloying," International Journal of Refractory Metals and Hard Materials, vol. 28, no. 2, pp. 211-216, 2010.

[12] M. Zakeri, M. R. Rahimipour, S. K. Sadrnezhad, and R. Yazdanni-rad, "Preparation of alumina-tungsten carbide nanocomposite by mechano-chemical reduction of $\mathrm{WO}_{3}$ with aluminum and graphite," Journal of Alloys and Compounds, vol. 491, no. 1-2, pp. 203-208, 2010.

[13] H. Romanus, V. Cimalla, J. A. Schaefer, L. Spiess, G. Ecke, and J. Pezoldt, "Preparation of single phase tungsten carbide by annealing of sputtered tungsten-carbon layers," Thin Solid Films, vol. 359, no. 2, pp. 146-149, 2000.

[14] A. C. Savarimuthu, H. F. Taber, I. Megat et al., "Sliding wear behavior of tungsten carbide thermal spray coatings for replacement of chromium electroplate in aircraft applications," Journal of Thermal Spray Technology, vol. 10, no. 3, pp. 502-510, 2001.

[15] D. Lou, J. Hellman, D. Luhulima, J. Liimatainen, and V. K. Lindroos, "Interactions between tungsten carbide (WC) particulates and metal matrix in WC-reinforced composites," Materials Science and Engineering A, vol. 340, no. 1-2, pp. 155162, 2003.

[16] J. Zhang, J. H. Lee, C. W. Won, S. S. Cho, and B. S. Chun, "Synthesis of $\mathrm{Al}_{2} \mathrm{O}_{3}$-WC composite powder by SHS process," Journal of Materials Science, vol. 34, no. 21, pp. 5211-5214, 1999.

[17] M. Razavi, M. R. Rahimipour, and A. H. Rajabi-Zamani, "Synthesis of nanocrystalline TiC powder from impure Ti chips via mechanical alloying," Journal of Alloys and Compounds, vol. 436, no. 1-2, pp. 142-145, 2007.

[18] B. Cullity and S. Stock, Elements of X-ray Diffraction, AddisonWesley Reading, Boston, Mass, USA, 1978.

[19] D. A. Porter, K. E. Easterling, and M. Y. Sherif, Phase Transformations in Metals and Alloys, CRC Press, Boca Raton, Fla, USA, 3rd edition, 2009.

[20] S. S. R. Tousi, R. Y. Rad, E. Salahi, I. Mobasherpour, and M. Razavi, "Production of Al-20 wt. $\% \mathrm{Al}_{2} \mathrm{O}_{3}$ composite powder using high energy milling," Powder Technology, vol. 192, no. 3, pp. 346-351, 2009.

[21] D. R. Gaskell, Introduction to the Thermodynamics of Materials, Taylor \& Francis, New York, NY, USA, 5th edition, 2008. 

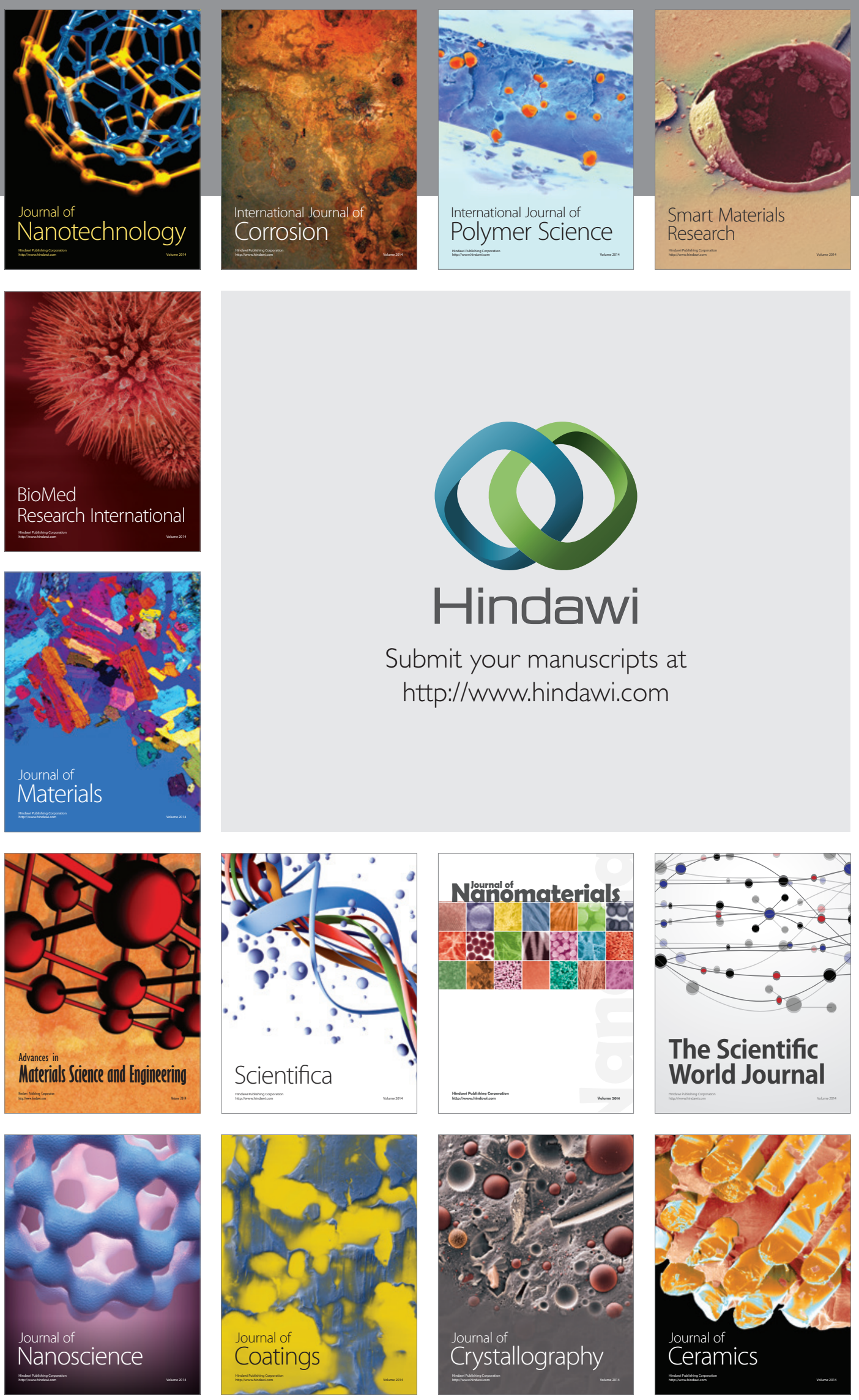

The Scientific World Journal

Submit your manuscripts at

http://www.hindawi.com

\section{World Journal}

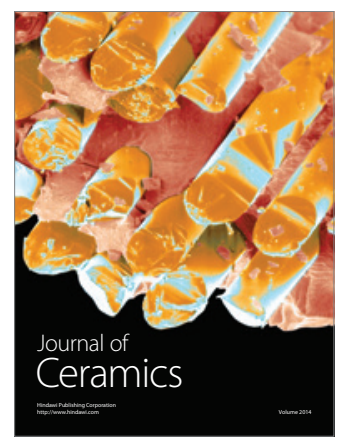

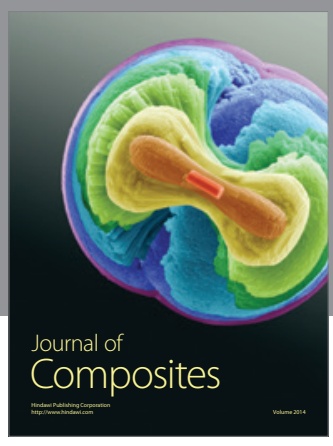
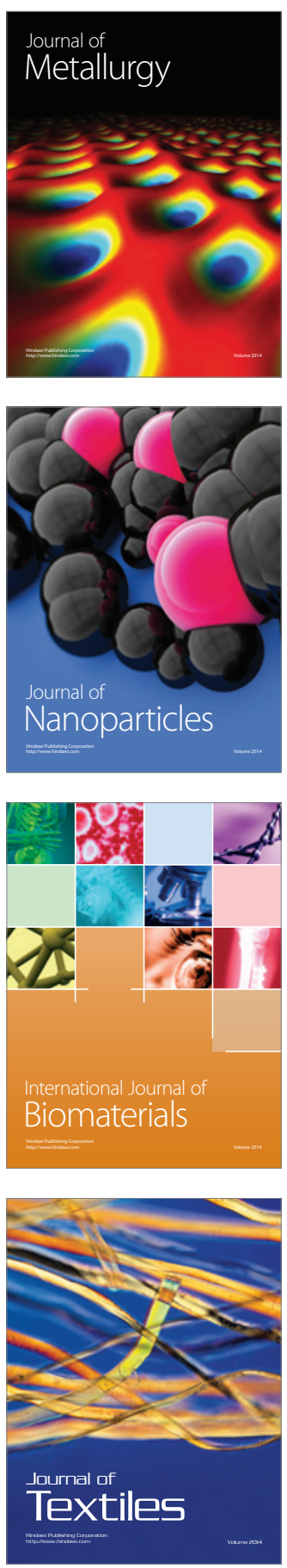